\title{
Editorial
}

\section{Preface: Proceedings of the 7th International Electronic Conference on Sensors and Applications ${ }^{\dagger}$}

\author{
Stefano Mariani ${ }^{1, *}$, Thomas B. Messervey ${ }^{2, *}$, Alberto Vallan ${ }^{3, *}$, Stefan Bosse ${ }^{4, *}$ and \\ Francisco Falcone ${ }^{5, *}$ \\ 1 Department of Civil and Environmental Engineering, Politecnico di Milano, Piazza L. da Vinci 32, \\ 20133 Milano, Italy \\ 2 Research to Market Solution s.r.l., Via Fratelli Cuzio 42, 27100 Pavia, Italy \\ 3 Department of Electronics and Telecommunications, Politecnico di Torino, Corso Duca Degli Abruzzi 24, \\ 10129 Torino, Italy \\ 4 Department of Mathematics and Computer Science, University of Bremen, 28359 Bremen, Germany \\ 5 Department of Electrical, Electronic and Communication Engineering, Public University of Navarre, \\ 31006 Pamplona, Navarra, Spain \\ * Correspondence: stefano.mariani@polimi.it (S.M.); thomas.messervey@r2msolution.com (T.B.M.); \\ alberto.vallan@polito.it (A.V.); sbosse@uni-bremen.de (S.B.); francisco.falcone@unavarra.es (F.F.) \\ + Presented at the 7th International Electronic Conference on Sensors and Applications, \\ 15-30 November 2020; Available online: https://ecsa-7.sciforum.net.
}

Published: 19 February 2021

This issue of Engineering Proceedings gathers the papers presented at the 7th International Electronic Conference on Sensors and Applications (ECSA-7), held online on 15-30 November 2020 through the sciforum.net platform developed by MDPI. The annual ECSA conference was initiated in 2014 on an online basis only, to allow the participation from all over the world with no concerns of travel and related expenditures. This type of conference looks particularly appropriate and useful because research concerned with sensors is rapidly growing, and a platform for rapid and direct exchanges about the latest research findings can provide a further burst in the development of novel ideas.

This year's edition saw increased collaboration online during virtual presentations, an increased number of submissions and dialogue and the inclusion of conference committee members worldwide. Video recordings of the sessions and open access to papers and presentations can be found online at https://ecsa-7.sciforum.net/.

ECSA-7 collected contributions concerning four thematic areas where sensors are changing science (Chemo and Biosensors, Physical Sensors, Sensor Networks, Applications) and five focus area sessions (Smart Cities, Structural Health Monitoring Technologies, Wearable Sensors, Optical Sensors and Women in Sensors), see https://ecsa-7.sciforum.net/. In total 115 technical contributions and 2 keynote presentations were gathered, and all went through an independent peer-review process. During the conference, 6 live sessions held online successfully.

A companion special issue of Sensors, see https://www.mdpi.com/journal/sensors/special_ issues/ecsa7, will collect full-length versions of selected papers.

We would also like to warmly thank Stefanie Tian and Nora Zhang for their extraordinary editorial work and support before, during and right after ECSA-7.

Publisher's Note: MDPI stays neutral with regard to jurisdictional claims in published maps and institutional affiliations.

(C) 2021 by the authors. Licensee MDPI, Basel, Switzerland. This article is an open access article distributed under the terms and conditions of the Creative Commons Attribution (CC BY) license (http://creativecommons.org/licenses/by/4.0/). 